\title{
Causal Relationships in the Balanced Scorecard: A Path Analysis
} Approach

\author{
Yael Perlman \\ Department of Management, Faculty of Social Sciences, Bar-Ilan University, Ramat-Gan 52900, Israel
}

Tel: 972-3-531-8143Ｅ-mail: yael.perlman@biu.ac.il

Received: January 27, 2013

Accepted: February 8, $2013 \quad$ Online Published: February 15, 2013

doi:10.5430/jms.v4n1p70

URL: http://dx.doi.org/10.5430/jms.v4n1p70

\begin{abstract}
We use path analysis to identify causal relationships between different performance measures in each of the four perspectives defined in the balanced scorecard and examine the influence of time lag on relationships between perspectives. We analyze performance data from a real high-tech company. Our results point to a direct relationship between leading measures in the learning and growth perspective and lagging measures in the financial perspective. Our findings also support the existence of a path of "Learning $\rightarrow$ Production Efficiency $\rightarrow$ Quality", reflecting the fact that the more the organization invests in learning and in developing its human capital, the better the production efficiency and product quality will be in the same year. We identify an additional direct path "Customer Service $\rightarrow$ Profit", reflecting a significant positive relationship between the customer and profit in the same year. Finally a "Growth $\rightarrow$ Sales" path exists implies that improvement in the growth of the firm is followed by a positive effect on the firm's sales one year later.
\end{abstract}

Keywords: Balanced scorecard, Performance management, Path analysis

\section{Introduction}

In today's competitive marketplace, managers must use performance measurement tools in order to create measurable milestones on the way to implementing their organizations' strategy and vision. It is well known that standard financial measures by themselves are not enough to encapsulate organizational goals, and that a more comprehensive measurement system is required (Mooraj, Oyon, \& Hostettler, 1999; Norreklit, 2000). Verbeeten and Boons (2009) argued that strategic priorities affect managers' use of non-financial performance measurement systems. They showed that as growth becomes a more important priority to an organization, the company becomes more likely to adopt specific non-financial performance measures (e.g., employee measures, customer support and delivery measures, quality measures and production measures). Several frameworks incorporating such performance measures have been developed, including the balanced scorecard (BSC; Kaplan \& Norton, 1992), the performance pyramid (Lynch \& Cross, 1991) and the performance prism (Neely, Adams, \& Kennerley, 2002).

In this paper we focus on the BSC, which is widely used in many industries all over the world (see a review in Nilsson \& Kald, 2002). In this framework, companies translate the vision and strategy of a business unit into objectives and measures reflecting the following four perspectives:

(i) The Financial Perspective: how the company wishes to be perceived by its shareholders;

(ii) The Customer Perspective: how the company wishes to be perceived by its customers;

(iii) The Internal Business Process Perspective: the processes in which the company must excel in order to satisfy its shareholders and customers;

(iv) The Learning and Growth Perspective: the changes and improvements that the company must achieve to implement its vision.

Kaplan and Norton (2004a, 2004b) emphasized the causal relationships between the four perspectives. Specifically they defined relationships between lagging measures (financial measures) and performance-driving measures (such as internal process and growth and learning). Other researchers (Norreklit, 2000; Tan, Platts, \& Noble, 2004) have questioned the assumption of unidirectional causality and claim that the relationships among the four perspectives are actually relationships of interdependence and bi-directional causality. Akkermans and Oorschot (2005) used a 
system dynamics approach with causal diagramming in order to identify relationships between performance measures of the BSC. Huang and colleagues (2009) showed that by understanding causal relationships and strategy-driven processes, organizations can use non-financial measures to project financial performance. Using a dynamic-integrative model they proved the existence of positive-influence relationships between the learning and growth perspective, the customer perspective and the financial perspective. In addition, they found that internal processes mediate the relationship between the learning and growth perspective and the financial perspective. Patel, Chaussalet, and Millard (2008) used a causal loop model to identify complex relations between performance measures and to examine how a change in one measure affects the rest of the system. Wang, $\mathrm{Lu}$, and Chen (2010) suggested that measures from different perspectives may contradict and refute one another, and therefore that it is necessary to look at hierarchical relationships and vertical relationships among measures.

In this paper we empirically examine relationships between the four perspectives of the BSC. Using path analysis, we explore our propositions about the relationship between performances measures in order to identify direct and indirect influences among measures corresponding to different perspectives. Path analysis was originally introduced by Wright (1921) and later popularized in the social sciences by Duncan (1966) and Blalock (1971). Path analysis is a statistical tool used to evaluate whether the correlations between variables in a given data set reflect the casual hypotheses specified in the model. In this paper we develop two path models as explained in section 3 .

In order to examine the existence of time-lagged causal relationships among the four perspectives we carry out a case study using performance measurement data from an Israeli high-tech firm and study the influence of time on financial and non-financial measures. Specifically we analyze how measures relating to the learning and growth perspective influence internal processes in the same year, and how they influence customer-related and financial performance in the following year. In examining the role of time lag, we expand on the work of Yang and Tung (2006), who empirically investigated causal relationships among the performance measures of the BSC in the hospital system in Taiwan.

\section{Data: The Case Study}

The data we analyze concern an Israeli high-tech firm that specializes in advanced wireless communication systems for manned and un-manned ground and airborne platforms. The firm states the following vision:

- To be the world's leading wireless communication company;

- To be known and recognized as a company of integrity, teamwork, openness and excellent human resources;

- To meet the customers' needs to their satisfaction, while maintaining a high level of service.

The firm's business goals are:

- To preserve its status as a technological leader in developing wireless communication systems in Israel;

- To penetrate deeper into the global market and to establish its status as a leading supplier of advanced data link systems and un-manned tools;

- To expand the company's activity in the field of mesh communication systems.

The company currently measures its performance by using about 30 indicators that reflect the organization's objectives and that have been characterized by the company's management as main success factors. The indicators are organized in an hierarchical structure that matches the company's organizational structure to a large extent (see Figure 1). We classified the measures into the four perspectives of the BSC model, each perspective is colored differently.

In order to examine the essential relationships between measures corresponding to different perspectives, in this case study we focus on a smaller sub-group of measures, summarized in Table 1. We classify measures according to whether they are leading measures (performance-driving measures, i.e., internal processes and learning and growth) or lagging measures (results, i.e., financial measures and customer-related measures). Data for each measure, gathered from 19 projects executed by the firm during the years 2009-2011, are provided in the appendix.

Measurements relating to the financial perspective reflect the company's strategic objectives in terms of ensuring value for shareholders and maximizing the organization's resources. In this perspective we focus on net profit and sales turnover, which indicate business success at the project level and at the company level. 
Measurements relating to the customer perspective show how the company meets the demands and expectations of its customers in terms of customer satisfaction based on a survey the company performs. The measures "on-time delivery" and "returns within warranty" indicate the level of service provided to the customer.

The internal processes perspective focuses on defining and implementing effective processes, and on correct management of the firm's operations unit. This perspective comprises two main aspects that the company has identified as critical to success: quality and production efficiency. Regarding quality, the "records quality" measure reflects the quality of the documents written by the research and development (R\&D) department, which are later used in production processes. The better the documents, the better the transfer of knowledge from R\&D to the production department, and thus the production process is more efficient and the products are of higher quality. Quality is manifested by a low "price of non-quality" measure. The "meeting milestones" measure reflects the organization's ability to construct work plans, to set quality objectives and to efficiently move from one stage to the next, according to the division's milestones. Production efficiency is measured by "first-time yield" (FTY), i.e., the proportion of goods from a manufactured lot that meet pre-specified quality standards.

The learning and growth perspective emphasizes the importance of investing in the human resource in order to motivate employees and to encourage professionalism, creative thinking and innovation. Measurements relating to this perspective include the "new product introduction" (NPI) measure, which provides an indication of the firm's level of innovation, the "training hours" measure, which reflects the extent to which the company invests in training and learning, the "internal audit" measure, which expresses the degree to which the internal audit function is meeting its objectives and agreed quality standards, and the "employee satisfaction" measure, which reflects the employee attitude, motivation and satisfaction.

\section{Hypotheses and Model Development}

Path analysis is a statistical method we use to examine the comparative strength of direct and indirect relationships between performance perspectives. The time lag relationships between the four perspectives in the path model are expressed in terms of correlations among the measurements corresponding to the various perspectives. In order to analyze the influence of the time dimension, we assume that the influence of learning and growth activities on internal processes takes effect during the same year, whereas the influence of these activities on customer and financial performance occurs in the following year.

Based on interviews of the company's managers and on the literature review (Yang and Tung, 2006; Patel, Chaussalet, and Millard, 2008; Wang, $\mathrm{Lu}$, and Chen, 2010) we propose the following conceptual diagram and hypotheses with respect to the causal relationships among the four perspectives of the Balanced scorecard, where an arrow illustrates the expected casual sequence (see Figure 2). The diagram shows direct and indirect paths by following the arrows. Direct path is a single path away, while indirect path are compound pathways made up of several direct pathways. We use AMOS software to test the following hypotheses:

Hypothesis 1 . Growth has a positive influence on quality.

Hypothesis 2. Learning has a positive influence on production efficiency.

Hypothesis 3. Growth has a positive influence on sales.

Hypothesis 4. Production efficiency has a positive influence on quality.

Hypothesis 5. Quality has a positive influence on customer service.

Hypothesis 6. Production efficiency has a positive influence on customer service.

Hypothesis 7. Customer service has a positive influence on profit.

Hypothesis 8. Customer service has a positive influence on sales.

Hypothesis 9. Customer service has a positive influence on customer satisfaction.

In order to consider time lag effects on each model the hypotheses were tested twice, according to the data collected in 2009-2010, and in 2010-2011, $t$ denotes the first year and and $t+1$ denotes the consecutive year. We examined two different models using different sets of performance measures (see the corresponding path diagrams in Figures 3 and 4). These models were constructed from only the specific relevant paths based on interviews of the company's managers.

\section{Results}

Results of our empirical analysis for Model 1 are reported in Figure 5 and Figure 6, regarding data gathered from 19 projects executed by the firm collected in the years 2009-2010 and 2010-2011, respectively. A standardized path 
coefficient, near the arrow, indicates the direction (either plus or minus) and the magnitude of influence between the measures. A full arrow represents a significant path. A dashed arrow represents an insignificant path.

The significant findings for Model 1 for years 2009, 2010 and 2011 are as follows:

Training hours has positive effects on first time yield $(p<0.01, \beta=0.68$ for $2009-2010 ; p<0.01, \beta=0.89$ for $2010-2011)$. Improvement in first time yield decreased price of non-quality $(p<0.01, \beta=-0.71$ for 2009-2010; $p<$ $0.05, \beta=-0.95$ for 2010-2011). Thus we found a significant indirect relationship between training hours and price of non-quality, and can construct the path "Learning $\rightarrow$ Production Efficiency $\rightarrow$ Quality". Returns within warranty has negative effects on net profit ( $p<0.01, \beta=-0.67$ for 2009-2010; $p<0.05, \beta=-0.58$ for 2010-2011). Thus there exists a direct path "Customer Service $\rightarrow$ Profit". Note that both paths are within the same year (no time lag).

The significant findings for Model 1 for years 2010 and 2011 are as follows:

Employee satisfaction in 2010 decreased price of non-quality in $2011(p<0.05, \beta=-0.39$ for 2010-2011). Therefore there exists a direct path "Growth $\rightarrow$ Quality". In addition, a significant relationship between training hours and price of non-quality ( $p<0.1, \beta=0.73$ for 2010-2011) occurs thus a direct path "Learning $\rightarrow$ Quality" exists.

Improvement in first time yield in 2010 has negative effects on returns within warranty $(p<0.05, \beta=-0.49$ for 2010-2011). A decrease in returns within warranty in 2010 increased customer satisfaction $(\mathrm{p}<0.01, \beta=-0.71$ for 2010-2011). Therefore two indirect paths with time lag exist for the years 2010 and 2011: the path of "Learning $\rightarrow$ Production Efficiency $\rightarrow$ Customer Service $\rightarrow$ Profit" and the path of "Learning $\rightarrow$ Production Efficiency $\rightarrow$ Customer Service $\rightarrow$ Customer Satisfaction"

The results for Model 2 based on empirical data collected in the years 2009-2010 is presented in Figure 7. The results for years 2010-2011 is presented in Figure 8.

A significant findings for Model 2 for years 2009, 2010 and 2011 is that a high innovation level (NPI) led to an increase in sales on the successive year $(p<0.05, \beta=0.41$ for 2009-2010; $p<0.01, \beta=0.59$ for 2010-2011). Therefore a "Growth $\rightarrow$ Sales" path exists.

The significant findings for Model 1 only for years 2010 and 2011 are as follows:

An increase in internal audits in 2010 led to an improvement in record quality $(p<0.05, \beta=-0.46)$. An improvement in record quality in 2010 led to an increase in on-time delivery in $2011(p<0.05, \beta=-0.43)$. Thus there exists a path" Growth $\rightarrow$ Quality $\rightarrow$ Customer Service".

The model's goodness of fit to the sample data was examined according to a number of measures as depicted in Table 2. First, we examined the goodness of fit using a Chi-squared test $\left(\chi^{2}\right)$, which shows acceptable fit for Model 1 and Model 2 for 2010 and 2011.

A relative Chi-squared measure $\left(\chi^{2} / d f\right)$ with a value smaller than 2 signifies a "good" fit between the described model and the model calculated according to data. Such a result was obtained for the following models: Model 1 in 2009-2010, Model 1 in 2010-2011 and Model 2 in 2010-2011. However, in Model 2 for the years 2009-2010, the relative Chi-squared value is larger than 2, and therefore signifies a "less good" fit; that is, there is a difference between the described model and the model that was calculated according to data.

\section{Discussion}

We analyze the influence of each perspective of the balanced scorecard over the three years: 2009-2011. Analyzing the influence of learning and growth perspective we found that investment in learning led to significant improvement in production efficiency in these same years. The training program was focused on improving production and this result confirms hypothesis 2 that the organizational learning has a positive influence on the internal processes perspective.

A "Growth $\rightarrow$ Sales" path exists implies that improvement in the growth of the firm is followed by a positive effect on the firm's sales one year later. Greater new product introductions led to higher sales turnover in the following year, supporting hypothesis 3 . This result points to a direct relationship between leading measures in the learning and growth perspective and lagging measures in the financial perspective due to the company's organizational strategy, which states that the company must each year invest many resources in research and development of new products 
and technologies, in order to maintain its status as a technological leader and increase its competitiveness in the market.

The main finding that stem from this study with regard to the influence of the internal business process perspective is an internal significant relationship between improving production efficiency and a decrease in price of non-quality, specifically repair costs of defective products went down significantly as the production efficiency went up. This result confirms our hypothesis that production efficiency has a positive influence on quality (hypothesis 4). In addition, this finding, combined with the findings of learning and growth perspective suggests the existence of a path "Learning $\rightarrow$ Production Efficiency $\rightarrow$ Quality", reflecting the fact that the more the organization invests in learning and in developing its human capital, the better the production efficiency and product quality will be in the same year.

The main finding with regard to the influence of the customer perspective is a direct path "Customer Service $\rightarrow$ Profit", reflecting a significant positive relationship between the customer and profit in the same year, due to a reduction in returns. This result confirms the hypothesis 7 .

Our findings proved the validity of the following hypotheses for both 2009-2010 and 2010-2011:

Hypothesis 2: Learning has a positive influence on production efficiency.

Hypothesis 3: Growth has a positive influence on sales.

Hypothesis 4: Production efficiency has a positive influence on quality.

Hypothesis 7: Customer Service has a positive influence on profit.

Focusing only at the results for the years 2010-2011we found that the following hypotheses were supported:

Hypothesis 1: Growth has a positive influence on quality.

Hypothesis 5: Quality has a positive influence on customer service.

Hypothesis 6: Production efficiency has a positive influence on customer service.

Hypothesis 9: Customer service has a positive influence on customer satisfaction.

\section{Conclusions}

We used path analysis to study the causal relationships between specific performance measures corresponding to the four BSC perspectives, taking time lag into account. We observed that organizational learning substantially improved internal processes in the same year. We found that the organization's growth, which was manifested in development and production of innovative and technologically-advanced products, was associated with increased sales in the following year. We observed that customer service improved profit in the same year.

One potential limitation of our study is that the data for customer satisfaction were collected by questionnaires. The validity of the research is therefore subject to the quality of the data and to the manner in which the questionnaires were analyzed. Another limitation is related to the sample size: The number of projects examined (19 projects) constitutes a small sample for the path analysis method. In addition there is probably a partial dependence among projects, as all projects were performed in the same firm. Future research should be conducted on a larger sample and explore the effect of other performance measures.

\section{References}

Akkermans, H. A., \& Oorschot, K. E. (2005). Relevance assumed: a case study of balanced scorecard development using system dynamics. Journal of Operational Research Society, 56, 931-941.

Blalock, H. M. (1971). Causal models in social sciences. Chicago: Aldine Publishing Co.

Duncan, O. D. (1966). Path analysis-Sociological examples. American Journal of Sociology, 72, 1-16.

Huang, H. C., Chu, W. Y., Lai, M. C., \& Lin, L. H. (2009). Strategic linkage process and value-driven system: A dynamic analysis of high-tech firms in a newly-industrialized country. Expert Systems with Applications, 36, 3965-3974.

Kaplan, R. S., \& Norton, D. P. (1992). The balance scorecard: measures that drive performance. Harvard Business Review, 70, 71-79.

Kaplan, R. S., \& Norton, D. P. (1996). Using the balance scorecard as a strategic management system. Harvard Business Review, 74(1), 75-85. 
Kaplan, R. S., \& Norton, D. P. (2004a). Strategy maps: Converting intangible assets into tangible outcomes. Boston, MA: Harvard Business School Press.

Kaplan, R. S., \& Norton, D. P. (2004b). Measuring the strategic readiness of intangible assets. Harvard Business Review, 82(2), 52-63.

Lynch, R. L., \& Cross, K. F. (1991). Measure up! The essential guide to measuring business performance. London: Mandarin.

Mooraj, S., Oyon, D., \& Hostettler, D. (1999). The balanced scorecard: a necessary good or an unnecessary evil. European Management Journal, 17, 481-491.

Neely, A., Adams, C., \& Kennerley, M. (2002). The performance prism: The scorecard for measuring and managing business success. London: Financial Times Prentice Hall.

Nilsson, F., \& Kald, M. (2002). Recent advances in performance management: The Nordic case. European Management Journal, 20, 235-245.

Norreklit, H. (2000). The balance on the balanced scorecard-A critical analysis of some of its assumptions. Management Accounting Research, 11, 65-88.

Patel, B., Chaussalet, T., \& Millard, P. (2008). Balancing the NHS balanced scorecard. European Journal of Operational Research, 185, 905-914.

Tan, K. H., Platts, K., \& Noble, J. (2004). Building performance through in-process measurement: toward an 'indicative' scorecard for business excellence. International Journal of Productivity and Performance Managements, 53(3), 233-244.

Verbeeten, F. H. M., \& Boons, A. N. A. M. (2009). Strategic priorities, performance measures and performance: an empirical analysis in Dutch firms. European Management Journal, 27, 113-128.

Wang, C. H., Lu, I. Y., \& Chen, C. B. (2010). Integrating hierarchical balanced scorecard with nonadditive fuzzy integral for evaluating high technology firm performance. International Journal of Production Economics, 128, 413-426.

Wright, S. (1921). Correlation and causation. Journal of Agriculture Research, 20, 557-585.

Yang, M.-C., \& Tung, Y.-C. (2006). Using path analysis to examine causal relationships among balanced scorecard performance indicators for general hospitals: The case of a public hospital system in Taiwan. Health Care Manage Review, 31(4), 280-288.

Table 1. List of measures

\begin{tabular}{|c|c|c|c|c|}
\hline Perspective & Main Activities & Measures & $\begin{array}{c}\text { Leading / Lagging } \\
\text { Measurement }\end{array}$ & $\begin{array}{c}\text { Influence in Time } \\
\text { Dimension }\end{array}$ \\
\hline \multirow{2}{*}{ Financial } & Profit & Net profit & Lagging Measure & Year $\mathrm{t}+1$ \\
\hline & Sales & Sales turnover & Lagging Measure & Year $\mathrm{t}+1$ \\
\hline \multirow{3}{*}{ Customers } & $\begin{array}{l}\text { Customer } \\
\text { Satisfaction }\end{array}$ & Satisfaction Survey & Lagging Measure & Year $\mathrm{t}+1$ \\
\hline & \multirow[t]{2}{*}{ Customer Service } & $\begin{array}{c}\text { Returns within } \\
\text { warranty }\end{array}$ & Lagging Measure & Year $\mathrm{t}+1$ \\
\hline & & On-time delivery & Leading Measure & Year $\mathrm{t}+1$ \\
\hline \multirow{4}{*}{ Internal Processes } & $\begin{array}{l}\text { Production } \\
\text { Efficiency }\end{array}$ & First time yield & Leading Measure & Year t \\
\hline & \multirow{3}{*}{ Quality } & Price of non-quality & Leading Measure & Year t \\
\hline & & Records quality & Leading Measure & Year $\mathrm{t}$ \\
\hline & & Meeting milestones & Leading Measure & Year $\mathrm{t}$ \\
\hline \multirow{4}{*}{$\begin{array}{l}\text { Learning and } \\
\text { Growth }\end{array}$} & Learning & $\begin{array}{c}\text { Training hours per } \\
\text { employee }\end{array}$ & Leading Measure & Year $\mathrm{t}$ \\
\hline & \multirow{3}{*}{ Growth } & $\begin{array}{c}\text { New product } \\
\text { introduction rating }\end{array}$ & Leading Measure & Year $\mathrm{t}$ \\
\hline & & Internal Audit & Leading Measure & Year $\mathrm{t}$ \\
\hline & & $\begin{array}{c}\text { Employee } \\
\text { satisfaction }\end{array}$ & Leading Measure & Year $\mathrm{t}$ \\
\hline
\end{tabular}


Table 2. Overall goodness of fit of model to data

\begin{tabular}{|l|l|l|l|c|}
\hline $\begin{array}{l}\text { Model 2 } \\
2010 \text { \& 2011 }\end{array}$ & $\begin{array}{l}\text { Model 2 } \\
\text { 2009 \& 2010 }\end{array}$ & $\begin{array}{l}\text { Model 1 } \\
\text { 2010 \& 2011 }\end{array}$ & $\begin{array}{l}\text { Model 1 } \\
\text { 2009 \& 2010 }\end{array}$ & \\
\hline 24.995 & 47.04 & 21.4 & 22.87 & $\chi^{2}$ \\
\hline 0.202 & 0.001 & 0.26 & 0.195 & $P$ value \\
\hline 1.25 & 2.35 & 1.19 & 1.27 & $\chi^{2} / d f$ \\
\hline
\end{tabular}

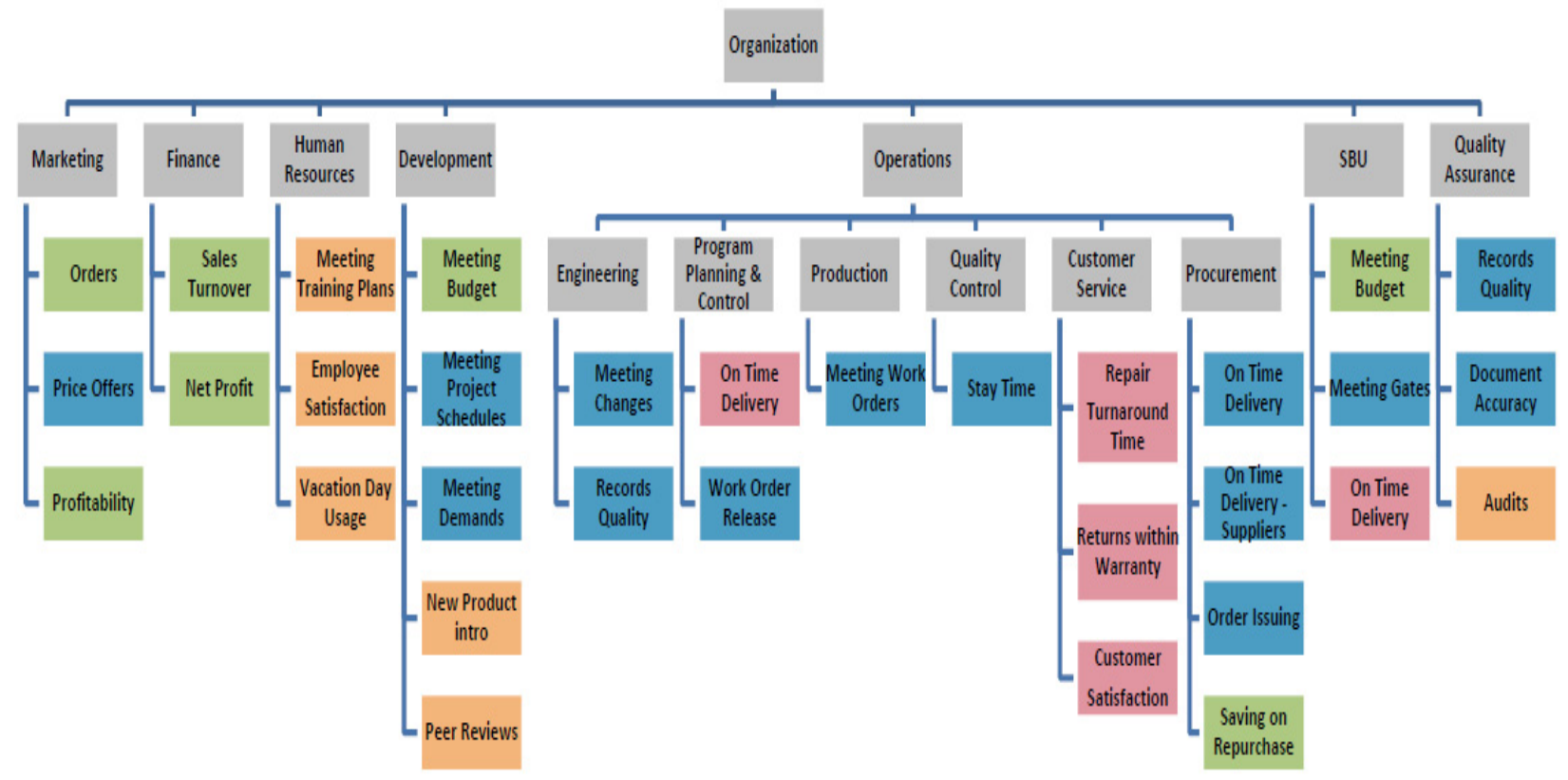

The green squares the financial perspective.

The pink squares the customer perspective.

The blue squares the internal business processes perspective.

The orange squares the learning $\&$ growth perspective.

Figure 1. Hierarchical measure structure

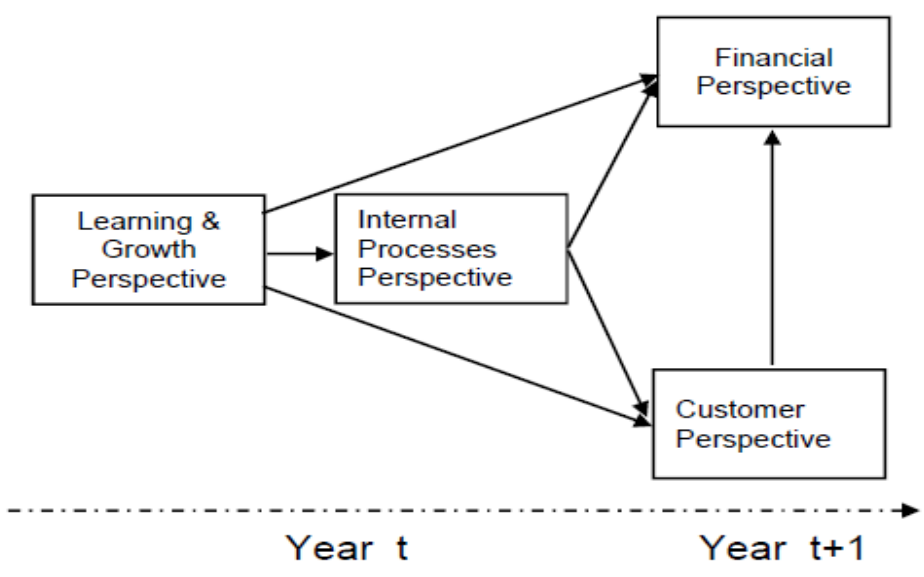

Figure 2. Conceptual diagram and research hypotheses 


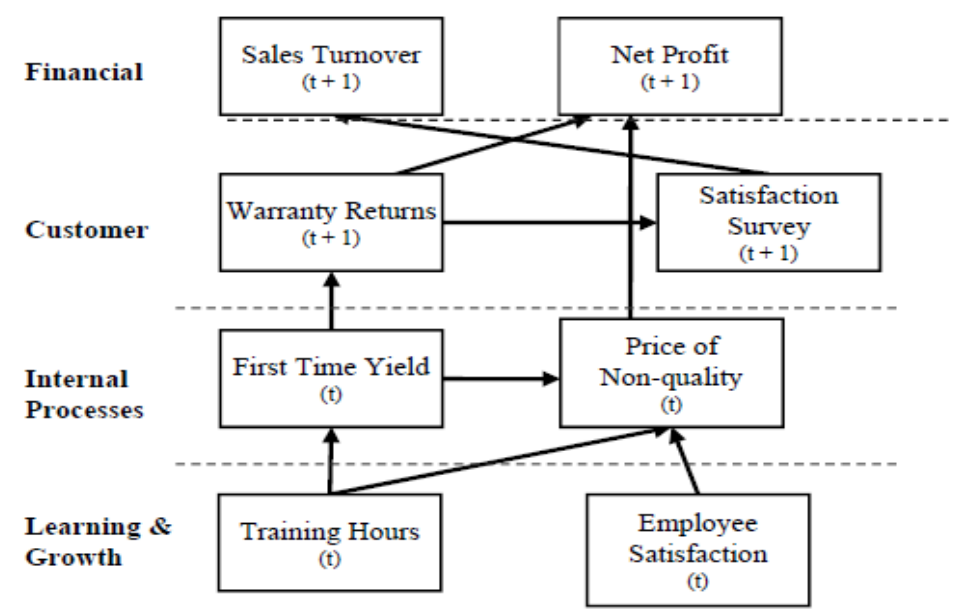

Figure 3. Proposed path analytic Model 1

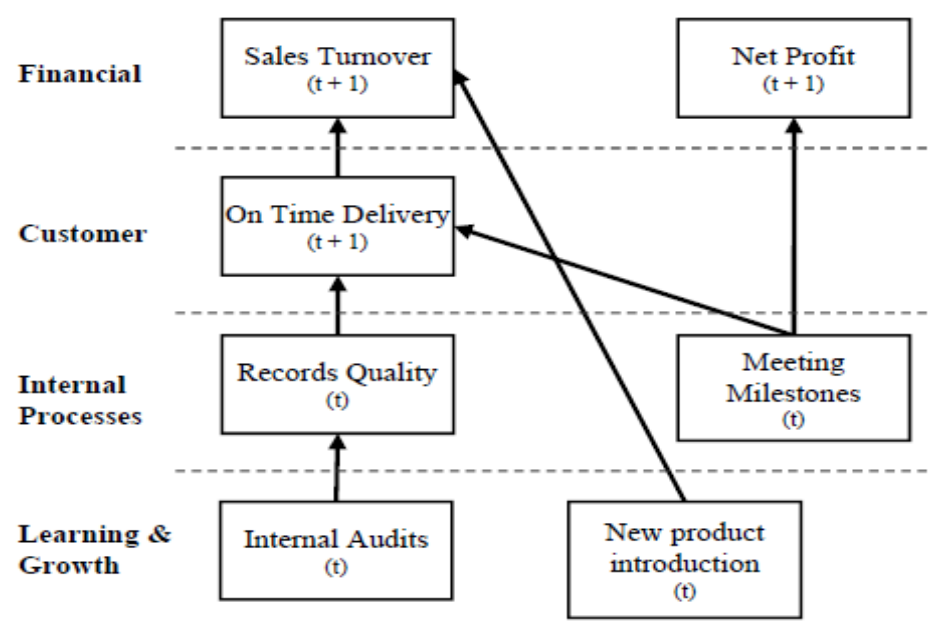

Figure 4. Proposed path analytic Model 2

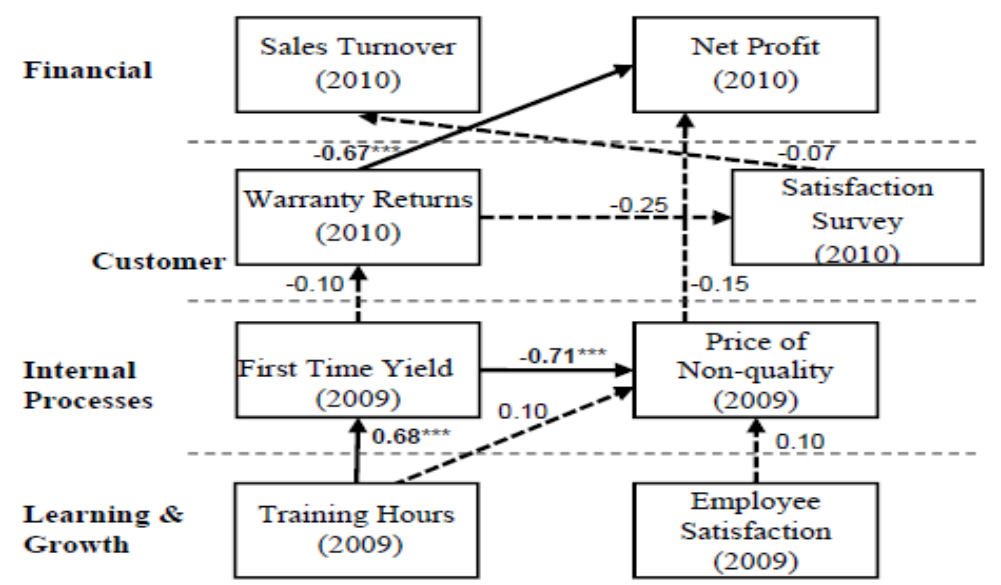

$* p<0.10 ; * * p<0.05 ; * * * p<0.01$

Figure 5. Relationships between measures in Model 1, Years 2009-2010 


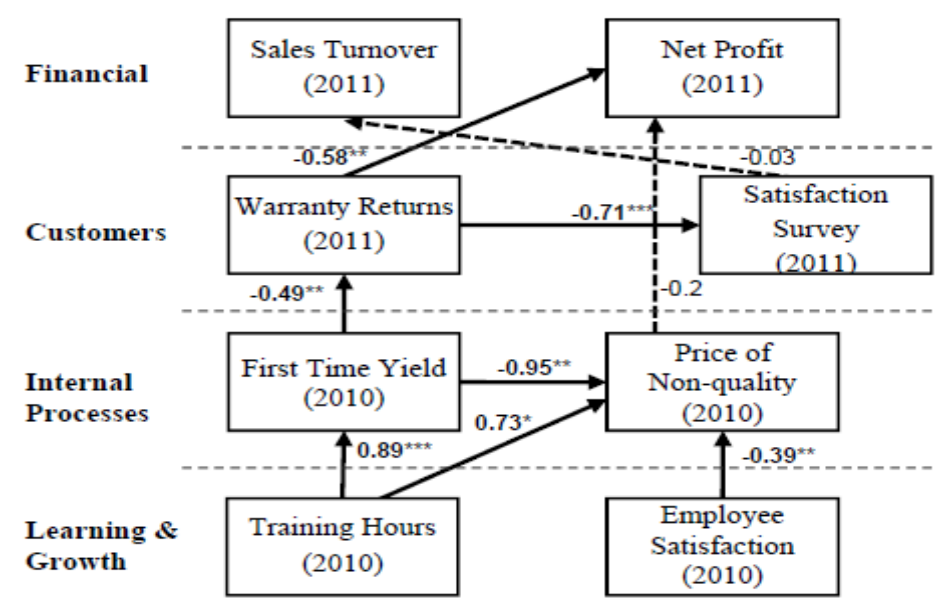

$* p<0.10 ; * * p<0.05 ; * * * p<0.01$

Figure 6. Relationships between measures in Model 1, Years 2010-2011

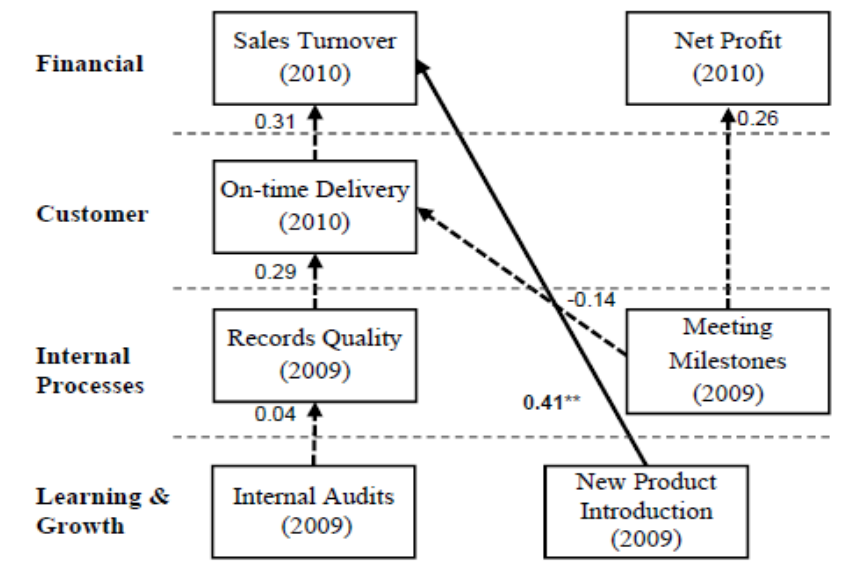

${ }^{*} p<0.10 ;{ }^{* *} p<0.05 ;{ }^{* * *} p<0.01$

Figure 7. Relationships between measures in Model 2, Years 2009-2010

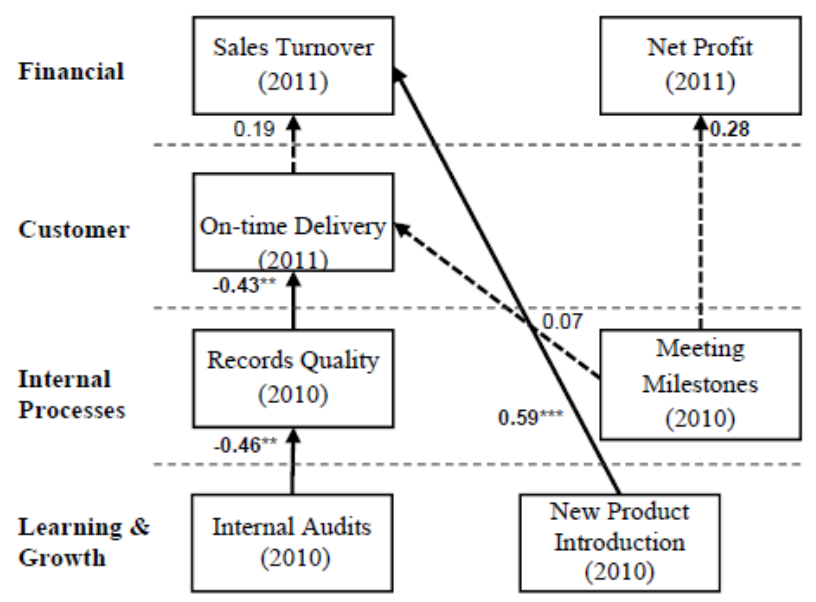

$* p<0.10 ; * * p<0.05 ; * * * p<0.01$

Figure 8. Relationships between measures in Model 2, Years 2010-2011 


\section{Appendix: Collected Measurement Data}

The following chart contains measurement data for 2009:

\begin{tabular}{|c|c|c|c|c|c|c|c|c|c|c|c|c|c|}
\hline $\begin{array}{l}\text { Project } \\
\text { number }\end{array}$ & $\begin{array}{l}\text { Net } \\
\text { profit }\end{array}$ & $\begin{array}{l}\text { Sales } \\
\text { turnover }\end{array}$ & $\begin{array}{l}\text { Satisfaction } \\
\text { Survey }\end{array}$ & $\begin{array}{l}\text { Returns } \\
\text { within } \\
\text { warranty }\end{array}$ & $\begin{array}{l}\text { On- } \\
\text { time } \\
\text { delivery }\end{array}$ & $\begin{array}{l}\text { First } \\
\text { time } \\
\text { yield }\end{array}$ & $\begin{array}{l}\text { Price } \\
\text { non- } \\
\text { quality }\end{array}$ & $\begin{array}{l}\text { Records } \\
\text { quality }\end{array}$ & $\begin{array}{l}\text { Meeting } \\
\text { milestones }\end{array}$ & $\begin{array}{l}\text { Training } \\
\text { hours }\end{array}$ & $\begin{array}{l}\text { New } \\
\text { product } \\
\text { intro rating }\end{array}$ & $\begin{array}{l}\text { Internal } \\
\text { Audit }\end{array}$ & $\begin{array}{l}\text { Employee } \\
\text { satisfaction }\end{array}$ \\
\hline 1 & 0.080 & 732 & 8 & 0.001 & 0.650 & 0.85 & 0.030 & 0.720 & 0.850 & 65 & 3 & 5.5 & 9 \\
\hline 2 & 0.025 & 3488 & 8.5 & 0.011 & 0.780 & 0.65 & 0.067 & 0.850 & 0.700 & 66 & 2 & 10 & 8.5 \\
\hline 3 & 0.032 & 838 & 7.5 & 0.010 & 0.880 & 0.75 & 0.015 & 0.700 & 0.800 & 71 & 2 & 3.7 & 9 \\
\hline 6 & 0.180 & 1183 & 8.5 & 0.037 & 0.720 & 0.85 & 0.030 & 0.900 & 0.850 & 88 & 2 & 3.9 & 8.5 \\
\hline 7 & 0.001 & 252 & 8.2 & 0.001 & 0.850 & 0.74 & 0.025 & 0.845 & 0.740 & 70 & 1 & 6.8 & 9 \\
\hline 8 & 0.154 & 1648 & 8.8 & 0.021 & 0.870 & 0.85 & 0.025 & 0.740 & 0.950 & 67 & 1 & 2.1 & 10 \\
\hline 12 & 0.216 & 1750 & 8.1 & 0.005 & 0.780 & 0.75 & 0.011 & 0.690 & 0.850 & 78 & 1 & 3.7 & 7.5 \\
\hline 13 & 0.030 & 1188 & 8.2 & 0.003 & 0.810 & 0.90 & 0.015 & 0.900 & 0.900 & 91 & 1 & 1.6 & 9 \\
\hline 14 & 0.018 & 324 & 8.8 & 0.010 & 0.750 & 0.94 & 0.014 & 0.700 & 0.950 & 90 & 2 & 1.4 & 9 \\
\hline 15 & 0.015 & 10385 & 8.3 & 0.024 & 0.870 & 0.85 & 0.024 & 0.890 & 0.875 & 78 & 2 & 3.3 & 8.5 \\
\hline 16 & 0.080 & 1458 & 7.8 & 0.025 & 0.840 & 0.75 & 0.040 & 0.850 & 0.750 & 72 & 1 & 3.9 & 8 \\
\hline 17 & 0.025 & 3370 & 8.5 & 0.005 & 0.900 & 0.75 & 0.020 & 0.810 & 0.850 & 70 & 2 & 5.8 & 8.5 \\
\hline 18 & 0.180 & 1750 & 7.7 & 0.020 & 0.890 & 0.87 & 0.020 & 0.900 & 0.910 & 90 & 1 & 1.7 & 10 \\
\hline
\end{tabular}

